8-2004

\title{
Does family-centered out-of-home care work? Comparison of a family-centered approach and traditional care.
}

\author{
Cathleen A. Lewandowski \\ Cleveland State University, c.lewandowski@csuohio.edu \\ Lois Pierce \\ University of Missouri - St Louis
}

Follow this and additional works at: https://engagedscholarship.csuohio.edu/clsowo_facpub

Part of the Social Work Commons

How does access to this work benefit you? Let us know!

Publisher's Statement

(c) Oxford University Press for National Association of Social Workers.

\section{Recommended Citation}

Lewandowski, Cathleen A. and Pierce, Lois, "Does family-centered out-of-home care work? Comparison of a family-centered approach and traditional care." (2004). Social Work Faculty Publications. 26. https://engagedscholarship.csuohio.edu/clsowo_facpub/26

This Article is brought to you for free and open access by the School of Social Work at EngagedScholarship@CSU. It has been accepted for inclusion in Social Work Faculty Publications by an authorized administrator of EngagedScholarship@CSU. For more information, please contact library.es@csuohio.edu. 


\title{
Does family-centered out-of-home care work: Comparison of a family-centered approach and traditional care
}

\author{
Cathleen A. Lewandowski and Lois Pierce
}

This research assessed the effectiveness of a familycentered approach to out-of-home care in reunifying children with their families by comparing differential exit rates of children whose families received familycentered services with children whose families received routine child welfare services. The sample included 472 children who were in foster care from 1994 to 1996 in Missouri. Survival analysis was used to calculate the probability that a child would be reunified with his or her family at a particular time and to compare the differential exit rates for the children who experienced subsequent placement during the study period. The authors used Cox regression analysis to compare the likelihood of reunification between the two groups. Findings indicate that during the latter part of the study, family-centered out-of-home care counties reunified children af a faster rate than comparison counties.

\section{Key words: child welfare; family-centered services; out-of-home care; reunification; survival analysis}

Catbleen A. Lewandowski, PhD, $A C S W$, is associate professor and director, School of Social Work, Wichita State University, 1845 Fairmount Drive, Wichita, KS 67260; $\varepsilon$-mail: catbleen.lewandowski@wichita.edu. Lois Pierce, $P h D, A C S W$, is professor and director, School of Social Welfare, University of Missouri, St. Louis. An earlier version of this article was presented at the Fifth Annual Conference of the Society for Social Work and Research, January 19-22, 2001, Atlanta.
T he implementation of the Adoption and Safe Families Act of 1997 (ASFA) (P.L. 105-89) makes it important for us to understand how best to support families whose children have been removed from them for maltreatment. Family-driven practice, in which families are treated as experts and collaborators in goal setting and mobilization of solutions, has produced successful outcomes (Briar-Lawson, 1998). Fraser and colleagues (1997) provided support for this approach in their review of family preservation services (FPS). They found that empowerment of parents, the use of collateral services, and an in vivo focus in which services are provided in a home or a community setting were common elements in successful family preservation programs. They also suggested that successful services are culturally sensitive, action oriented, and carried out in collaboration with family members.

Although family preservation services have not been as effective as hoped for in the prevention of placement (Cole, 1995; Fraser et al., 1997; Wells \& Tracy, 1996), there is evidence that intensive family preservation services are useful in improving family functioning and can be used as an initial response to families where maltreatment is a problem. Wells and Tracy suggested using FPS to assess a family's strengths and weaknesses, to meet critical concrete needs, and to plan intervention. Walton (1998) described a program using FPS that successfully reunited children with their families. Although the results at a six-year follow-up were somewhat mixed, the families receiving FPS were significantly more likely to be stabilized than a control group of children who received routine foster care services.

Timeliness is one of the guiding features of ASFA, which was implemented to move children quickly into permanent placements. For workers to achieve case goals within the ASFA time frames, they must ensure that families have individualized service plans 
and high-quality comprehensive services, while ensuring that children are safe. All staff need to collaborate with other service providers, quickly engage families in treatment, and determine the parents' capacity for change (U.S. Department of Health and Human Services, 2000). These conditions can be met if intensive assessment and planning with families occurs when a child first enters care. In other words, a family-centered approach to foster care that integrates effective components of FPS and is implemented as soon as the child enters care should ensure the safety of the child and decrease the time the child spends in foster care.

However, for FPS to be successful, assessment and planning should recognize and distinguish between problems that are easily resolved and problems that contribute to longer stays in care. For example, a number of studies have found that neglect is more difficult to treat than other types of abusc (Berry, 1992; Nelson \& Landsman, 1992; Terling, 1999). Evidence also suggests that the longer children remain in care, the probability that they will return home decreases, and the more placements they experience, the slower their return home (Goerge, 1990). A family's financial situation and poor relationships within a family were also found to impede reunification (Davis \& Ellis-MacLeod, 1994; Lawder, Poulin, \& Andrews, 1986; Lindsey, 1994). Children who are older, are from ethnic minority groups, or have more serious problems have remained longer in out-of-home care (Festinger, 1996; Jenkins \& Diamond, 1985; Milner, 1987); some studies suggested the effects of race and age are complex and mediated by other factors (Courtney, 1994).

As a response to the increasing numbers of children in foster care, Missouri's Division of Family Services (DFS), working with staff, foster parents, foster children, and birth parents, developed Family-Centered Out of Home Care (FCOHC), a program that incorporates many of the elements found to contribute to the effectiveness of FPS. We used survival analysis and Cox regression analysis to assess the effectiveness of FCOHC and the factors related to returning children in $\mathrm{FCOHC}$ home quicker than those in comparison sites.

Event history analysis has rarely been used in child welfare. Child welfare studies using event history analysis compared differential exit rates among a state's overall foster care population (Courtney, 1992; Goerge, 1990) or among racial groups (Benedict, White, \& Stallings, 1987; McMurtry \& Gwat-Yong, 1992). None of the studies examining differential exit rates assessed the effectiveness of a child welfare intervention.

Earlier research indicated that a family-centered approach was more successful than routine child welfare services in reunifying children who were in care longer than seven days (Lewandowski \& Pierce, 2002). The findings from this study could have significant implications for child welfare practice by demonstrating the benefits of family-centered approaches for timely reunification.

\section{MISSOURI'S FAMILY-CENTERED OUT-OF-HOME CARE MODEL}

Missouri DFS began implementing the FCOHC pilot project in 1995 . The primary difference between $\mathrm{FCOHC}$ and most family preservation models is that the goal of family preservation tends to be to prevent out-of-home placement, whereas the goal of FCOHC is to use family-centered principles to reunify children with their families once children have been placed. Another important difference is the intensity of services. In family preservation programs, workers have small caseloads, which allows them to spend a significant amount of time with each family. FCOHC workers have larger caseloads, ideally 12 families, which allows more time for intensive case management and individual family meetings than found in routine out-of-home care, where caseloads may be as high as 60 cases, but not as much as is allowed in family preservation programs.

To increase continuity of care, families are assigned a family social worker within 24 hours of the child being taken into protective custody. The family social worker serves as the family's case manager while the child is in out-of-home care and facilitates collaboration among the network of agencies providing services to the family. Instead of adhering to a schedule, family social workers are encouraged to engage in an ongoing assessment of a family's progress. The family social worker explains to the family that they are core members of the family support team, along with the placement provider and the family social worker. Other potential members of the team include treatment providers, the juvenile officer, guardian ad litem, family attorneys, school personnel, natural helpers or parent advocates, and any others who provide direct services to the family.

In the FCOHC model, team meetings are to take place within 72 hours of the out-of-home placement, with subsequent meetings in $30,60,90$, and 180 days. In contrast, comparison counties are required to hold review meetings at 30,90 , and 180 days. 
Team meetings bring families, DFS social workers, and collateral service providers together to develop and implement the reunification plan. Most important, families are encouraged to be active participants in the reunification, something that was not done regularly in routine foster care.

In $\mathrm{FCOHC}$ families can be referred for a range of services, including individual and family therapy, parenting education, drug counseling, financial assistance, help with finding housing, and job assistance. FCOHC workers planned on average more services for children and their families than the comparison counties (3.8 and 2.0, respectively), and families in pilot counties received slightly more than twice as many services as comparison county families (3.5 and 1.5, respectively). Workers in pilot groups also identified more goals on average than workers in comparison counties (2.2 and 1.5, respectively). These differences were statistically significant $[t(470)=3.9, p=.00]$. The planning of additional services seems to have increased the overall number of services provided, although it is not known how many services families and their children actually completed.

FCOHC appeared to be more strengths-based, as $\mathrm{FCOHC}$ workers identified an average of 2.4 strengths in their families, whereas comparison workers identified an average of 1.8 strengths. It should also be noted that although emphasized as part of the model, written assessments were found in only $59 \%$ of the case records in pilot counties compared with $41 \%$ of records in comparison counties.

\section{METHOD}

This study assessed the effectiveness of a familycentered approach to out-of-home care in reunifying children with their families by comparing differential exit rates of children whose families received $\mathrm{FCOHC}$ services with children whose families received routine child welfare services in Missouri.

Placement data were gathered from the state's database, and a record review form was used primarily to collect demographic data. Cronbach's alpha was used to test the correlations between two reviewers' responses on use of the record review form. As indicated by Cronbach's alpha of .98 , there was a high degree of internal consistency in the way reviewers recorded data on the form (Lewandowski \& Pierce, 2002).

Because earlier research indicated that on average children who received $\mathrm{FCOHC}$ and were in outof-home-care longer than seven days exited care sooner than children in comparison counties
(Lewandowski \& Pierce, 2002), we hypothesized that FCOHC county children would exit care sooner than comparison county children when key family and child characteristics and service variables were taken into account.

\section{Research Design}

The study design, which most closely resembled a nonequivalent control group design, compared the differential exit rates of children whose families received $\mathrm{FCOHC}$ services in pilot counties with those whose families received routine foster care services in the comparison counties.

\section{Sample}

The counties in this study were largely rural, with only a few counties containing metropolitan areas. They are fairly evenly distributed throughout the state. Missouri DFS used an application process to select pilot counties. To apply, interested county office directors described the steps they and their staff would take to implement the pilot FCOHC project in their county DFS offices. From this group of applicants, DFS selected 12 county DFS offices for the pilot project. DFS then identified six counties to serve as comparison sites, based on similarities in geographic region and overall caseload. Comparison counties provided access to their case records and had no additional requirements except to continue routine foster care services.

The sampling frame was the 1,037 children who had entered out-of-home care during the first 12 months of the study period in pilot and comparison counties as identified on DFS's computerized database. In the larger counties, children's records were randomly selected for review. Of the 494 cases reviewed, 22 children entered out-of-home-care before the project start date and were eliminated from the analysis. Complete date were obtained on 472 children, 294 from the pilot counties and 178 from comparison counties. These 472 children made up the sample.

There were staggered start dates for the pilot counties and their corresponding comparison counties, because the pilot began as soon as workers received training in FCOHC. After training, data were collected for 18 months in that county.

Based on state statistics, we anticipated that reunification in pilot counties would occur within 12 months after the initial placement and that many children who received FCOHC would be reunified within six to nine months after the initial placement. Also, we anticipated that most children in pilot 
counties would be reunified within six months. A six-month follow-up period provided 12 months to assess the number of children who experienced a subsequent placement. Although there was an 18month study period, data collection continued for an additional six months to account for the staggered start dates among the pilot counties.

The unit of analysis was the individual child. The consequence is that larger families may receive more weight in the data. However, although sibling groups had similar lengths of stay for the initial placement, there was less similarity in the subsequent placement. For example, it was not always the case that children from the same family re-entered out-of-home care during the study period. Consequently, including only one child from a family would omit the analysis of subsequent placements for the younger children in the family.

Characteristics of children in the two groups were similar, both in terms of gender and ethnicity and in the number of children from single-parent families. The sample was predominantly white $(90 \%)$. Of the children whose gender was known, $52 \%$ were girls; boys and girls were fairly equally distributed in both groups $\left[\chi^{2}(1, N=472)=.175, p=.91\right]$. Data indicated that $32 \%$ of children in pilot counties and $33 \%$ of children in comparison counties were from singleparent families.

The groups differed in terms of children's ages and number of previous placements. On average, children in the $\mathrm{FCOHC}$ pilot group were 9.9 years old, whereas children in the comparison group were 7.5 years old, and these differences were statistically significant $[t(4.70)=4.77, p=.00]$. The number of previous DFS placements recorded for children in this sample ranged from zero to 22 . Pilot county children had an average of 1.2 placements, and comparison county children had an average of .8 placements $[t(470)=2.38, p=.017]$. When considering only the children with previous placement history, the two groups were similar in the average number of placements: Pilot county children experienced on average 2.4 previous placements, and comparison county children experienced on average 2.3 previous placements $[t(217)=-.3, p=.76]$.

Although the children in the two groups shared similar characteristics, the number of children served by pilot counties ranged from seven to 155 , and the number of children served by comparison counties ranged from two to 97. Mean total placement days for pilot counties ranged from 16 days in a county that served nine children to 220 days in a county that served eight children. Similarly, mean total place- ment days for comparison counties ranged from three days in a county that served two children to 221 days in a county that served five children. Although there was a wide range of placement days, the two groups did not differ significantly in the primary reasons for removal: neglect ( $n=144)$, physical abuse ( $n=88$ ), sexual abuse ( $n=60)$, status offense $(n=47)$, parental request $(n=44)$, caregiver incarceration $(n=27)$, abandonment ( $n=22)$, homelessness $(n=7)$, and other reasons $(n=11)$.

\section{Variables}

The independent variable was group, or whether children and their families received FCOHC or routine out-of-home care services. The dependent variables were total placement days for the first and second out-of-home placement. The variable first placement days was measured as the total number of days children spent in out-of-home care during their initial placement within the 18-month study period. For the children who re-entered care, the variable second placement days was measured as the total number of days children spent in out-of-home care during their second placement.

The following variables were included in the analysis as covariates to control for other factors that could explain differences in the dependent variable of placement days: child's age, gender, reason for removal, parental involvement, services received, and child contacts. Child's age was a continuous variable, whereas gender and reason for removal were categorical variables. Parental involvement was measured by number of meetings attended by a parent. Meetings were held at 72 hours and at 30,60 , and 90 days.

The two service variables included as covariates were services and child contacts. Services was a continuous variable that indicated the total number of types of services the family received while the child was in out-of-home care. To mitigate the influence of a child's length of stay in measuring service intensity, child contacts was a ratio variable, in which the denominator was the total number of placement days, and the numerator was the total number of contacts, either in-person or by phone, that the worker had with the child while the child was in out-of-home care. The ratio variable indicated the total number of child contacts per day of out-of-home care.

\section{Data Analysis}

Survival analysis was used to calculate the probability that a child would be reunified at a particular point. Cox regression analysis was used to compare 
the likelihood of reunification between the two groups while including key demographic and service variables as covariates. Cox regression assumes that observations are independent and that the hazard ratio should be constant over time. This assumption, also known as the proportional hazards assumption, suggests that the proportionality of hazards from one case to another should not vary over time (SPSS, 1999). Furthermore, as Allison (1984) explained, the proportional hazards model is extremely nonrestrictive, so that even when the proportional hazards assumption is violated it may be a satisfactory approximation.

Survival analysis, or life tables, and Cox regression analysis are methods for modeling time-to-event data in the presence of censored cases. Censored cases are individuals who do not experience the event of interest within the study period (Luke, 1993). In this study, censored individuals were children who remained in out-of-home care at the end of the study period. Children are considered to have a chance of being reunified until they are either reunified or censored, which enables a researcher to construct unbiased estimates of the proportion of children remaining in out-of-home care at various points.

Hazard profiles for a given sample can be displayed as odds or as probabilities (Willet \& Singer, 1993). When the hazard probability for a given day is .2 , there is a $20 \%$ chance that children in that group will be reunified on that day and an $80 \%$ chance that they will not be reunified. In this example, the odds of reunification on that day were .2 to .8 , usually written as $1 / 4$ or 25 . Odds can be computed using the formula odds $=$ hazard $/(1$ - hazard $)$.

\section{FINDINGS}

\section{Time in Out-of-Home Care}

A summary of survival functions for pilot and comparison groups at interquartile points in time for children's initial placements is provided in Table 1. Each quartile represents the time at which an additional $25 \%$ of children were reunified. The comparison group reunified $25 \%$ of children within the first three days of entering out-of-home care, and the pilot counties reunified $25 \%$ of children within 26 days. The median lifetime is the time at which one-half of the sample has experienced the target event and half has not. There was an eight-day difference in median lifetimes between the two groups, with comparison counties reunifying half their children by day 99 , and pilot counties reunifying half their children by day 108 . In the latter part of the study, the pilot group reunified $75 \%$ of children within 234 days, compared with 319 days for the comparison group to reunify $75 \%$ of children.

As would be expected from differences in survival rates, the hazard rate was much higher for children in the comparison group than children in the pilot group during the initial days of placement. For example, children in the comparison group had a $19 \%$ chance of returning home within one day of out-of-home care, whereas children in the pilot group had a $10 \%$ chance. At about 200 days the two groups began to distinguish themselves; the pilot group exhibited increased hazard rates at 220 and 404 days, and the comparison group had its highest hazard rates at 271 and 451 days. Earlier research has shown that the chances of being reunified diminish the longer a child remains in out-of-home care (Fanshel, 1976; Finch, Fanshel, \& Grundy, 1986; Goerge, 1990). In contrast, these findings suggest that the FCOHC pilot counties were more successful than comparison counties in reunifying children who had been in out-of-home-care longer.

The survival rates for children experiencing a second placement were similar to the pattern that emerged for children's initial placement, reflecting some consistency in the manner in which each group approached reunification. As with the first placement,

\section{TABLE 1-Survival Function: Initial Placement of Children in Out-of-Home Core $(N=472)$}

\begin{tabular}{lccccc}
\hline & \multicolumn{2}{c}{$\begin{array}{c}\text { Pilot Group } \\
(n=294)\end{array}$} & & \multicolumn{2}{c}{$\begin{array}{c}\text { Comparison Group } \\
(n=178)\end{array}$} \\
\cline { 2 - 5 } $\begin{array}{l}\text { Quartile } \\
\text { Lifetimes }\end{array}$ & $\begin{array}{c}\text { Days by which \% } \\
\text { were reunified }\end{array}$ & $\begin{array}{c}\text { Children not reunified } \\
\text { at start of this day }\end{array}$ & $\begin{array}{c}\text { Days by which \% } \\
\text { were reunified }\end{array}$ & $\begin{array}{c}\text { Children not reunified } \\
\text { at start of this day }\end{array}$ \\
\hline $25 \%$ & 26 & 224 & 3 & 138 \\
$50 \%$ & 108 & 148 & 99 & 91 \\
$75 \%$ & 234 & 75 & 319 & 46 \\
\hline
\end{tabular}


the comparison group exhibited a slightly faster rate of reunification during the initial days of placement, whereas the pilot group was faster during the later days of placement. Although differences were not as pronounced as those observed for initial placements, the FCOHC pilot group was more successful in reunifying children who were in out-of-homecare longer than six months. Seventy-five percent of pilot children were reunified within 214 days. In contrast, $75 \%$ of comparison children were reunified within 279 days of experiencing their subsequent placement.

\section{Variables Related to Exit}

A Cox regression model was constructed to address whether children in the two groups had different chances of reunification when child's gender and age at placement, reason for removal, child contacts, parental involvement, and services received were taken into account. The question tested was "What is the effect of FCOHC and the covariates on reunification?" Table 2 provides coefficients (B values) for the variables included in the equation. The $\operatorname{Exp}(\mathrm{B})$ associated with each beta statistic indicates the percentage change in risk with each unit change in the covariate. As continuous variables, the $\operatorname{Exp}(B)$ for child's age, services, parental involvement, and child contacts estimates the percentage change in risk with each unit change in the covariate. As dichotomous variables, the $\operatorname{Exp}(\mathrm{B})$ for gender, reason for placement, and group indicate the relative risk, because the covariate takes only the values of 0 and 1 .

Child contacts, parental involvement, and group significantly affected the chance of reunification. The beta associated with parental involvement was negative, indicating that as the number of meetings attended increased, the chance of reunification decreased. Because the beta associated with child contacts was positive, the chance of reunification increased with an increase in worker contacts with the child while in out-of-home care. For example, every unit increase in the ratio variable of child contacts increased the possibility of reunification about $70 \%$. When examining reasons for removal, children were less likely to be reunified if they were removed for abandonment, sexual abuse, or at the parent's request; younger children had a greater chance of reunification; and families receiving fewer services had a greater chance of reunification, although none of these reached significance. Chi-square for the overall model was $63.904(d f=13, N=373, p=$ $.000)$. The chi-square tests whether any of the population B values are zero.

The pilot group consistently reunified children quicker than the comparison group (Figure 1). For example, $50 \%$ of children in the pilot group were reunified after approximately 80 days in out-ofhome care. In contrast, $50 \%$ of comparison group children were reunified after approximately 170 days

\section{TABLE 2-Statistics for Cox Regression Model: Factors Associated with Family Reunification of Children in Out-of- Home Core}

\begin{tabular}{lrrrrrr}
\hline Variable & B & SE & Wald & df & Sig. & Exp(B) \\
\hline Male & .317 & .172 & 3.402 & 1 & .065 & 1.373 \\
Child's age & -.001 & .016 & .001 & 1 & .970 & .999 \\
Reason for removal & & & 4.432 & 7 & .729 & \\
$\quad$ Abuse & .120 & .495 & .058 & 1 & .809 & 1.127 \\
$\quad$ Neglect & .142 & .486 & .085 & 1 & .770 & 1.153 \\
Abandonment & -.407 & .561 & .525 & 1 & .469 & .666 \\
Sexual abuse & -.161 & .511 & .099 & 1 & .753 & .851 \\
Status offense & .139 & .564 & .061 & 1 & .805 & 1.150 \\
Parent's request & -.144 & .550 & .068 & 1 & .794 & .866 \\
$\quad$ Incarceration & .017 & .565 & .001 & 1 & .976 & 1.018 \\
Child contacts & 1.993 & .466 & 18.328 & 1 & .000 & 7.337 \\
Parental involvement & .179 & .219 & 3.052 & 1 & .003 & .519 \\
Services & -.063 & .038 & 2.825 & 1 & .093 & .939 \\
Group & .875 & .209 & 16.887 & 1 & .000 & 2.356 \\
\hline
\end{tabular}




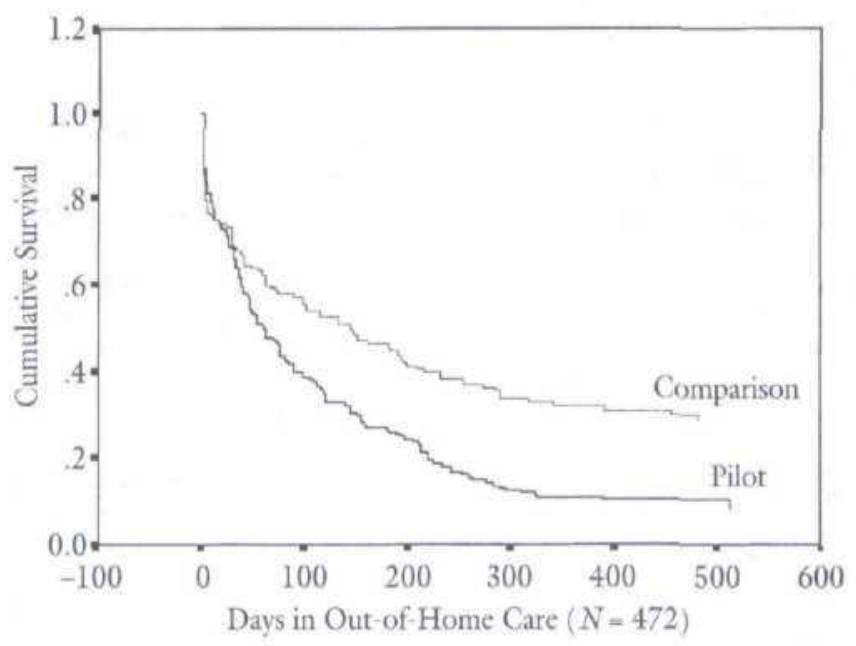

in out-of-home care. Thus, FCOHC had a significant effect on reunification.

\section{DISCUSSION}

Real differences in survival rates emerged during the latter part of the study period, with $\mathrm{FCOHC}$ reunifying children at a faster rate than comparison counties. Thus, FCOHC seems to have greater success at reunifying children who were not likely to be reunified, lending support to the hypothesis that children receiving $\mathrm{FCOHC}$ services would exit outof-home care sooner than children in comparison counties. In terms of subsequent placements, these differences came earlier, lending further evidence to the benefits of FCOHC in reunifying children. These findings also support the utility of event history analysis in child welfare research, as the differences reported here cannot be observed using multiple or logistic regression analyses.

A comparison of the relative magnitude of survival rates within the first month and last six months in out-of-home care provide a valuable perspective on how FCOHC differs from routine child welfare services in reunifying children with their families. As described earlier, workers reunified $25 \%$ of the children entering out-of-home care in comparison counties within the first week of placement, compared with $25 \%$ of children within the first three weeks of placement in pilot counties. During the study, the juvenile courts encouraged FCOHC workers to di- vert children from out-of-home care, thus avoiding any placement. (In Missouri, the juvenile court, not DFS, has authority to remove children from their homes.) Although consistent data are lacking to substantiate this practice, our analysis suggests that many children who were returned home within the first week in the comparison counties could have been diverted from care, and we would expect children in the pilot counties to need more intensive intervention before returning home. Further research is needed to monitor diversion activities.

The pattern of reunification exhibited in the survival analysis suggests that $\mathrm{FCOHC}$ workers were actively involved in reunification throughout the study period, whereas comparison counties exhibited periods of tapering off, when little reunification took place. These data give evidence to one dimension of the FCOHC program, to reunify children as soon as the child and the family are ready, rather than wait until the next administrative review. When workers have large caseloads, the administrative review frequently triggers attention to a case. In FCOHC it appears that workers follow families more closely and are better able to determine when reunification should occur. This is a much better proposition for children, families, and DFS.

It also appears that $\mathrm{FCOHC}$ workers know families better because they spend more time with them. This is reflected in the larger number of strengthsbased goals set. Families receiving FCOHC also are 
referred to and use more services. However, families who use the most services are less likely to be reunified. This suggests there are children and families who are more troubled and that additional services for these families may not lead to reunification. It is important, then, to be able to identify these cases more quickly and to determine what services may be missing. The findings suggest that when children are admitted to out-of-home-care for physical abuse they are more likely to return home, which suggests those families may receive adequate services. These findings provide evidence that when workers know families better, stay in contact with children, and involve children and their families in intervention planning, children are more likely to be reunified. Additional research on how interventions are planned and provided would help us better understand how to match children and families with appropriate services.

\section{Limitations and Future Research}

First, although we were able to randomly select children in larger counties, we were not able to randomly assign counties to treatment or comparison conditions. County directors who applied to participate were willing to try new approaches to practice and may have been more innovative than other directors. Nonapplicant counties may have had large caseloads and been unable to assign workers to FCOHC. This affects the generalizability to other counties and states.

Second, during the study caseloads increased; however, the impact of caseload was not examined. In several smaller counties workers often carried several cases, and it was difficult to separate their FCOHC cases from their total caseload. This did not appear to affect the overall FCOHC outcomes.

Another possible "contaminant" was that pilot group children could be placed with foster families in nonpilot counties, or parents could move to nonpilot counties. In these cases, the service worker remained the pilot county worker. The reverse was also true. Children from comparison counties could be placed in pilot counties, but retained their worker and received services similar to those of children and families in comparison counties. These "crossovers" occurred infrequently.

These data suggest that there can be benefits to adopting a family-centered approach to out-of-home care. The study demonstrates the benefits of using survival analysis in family and child welfare research, as the differential reunification rates were not readily apparent through other forms of data analysis. Fur- ther research on FCOHC is needed to assess the extent to which benefits of a family-centered approach to out-of-home care are sustained over time.

\section{REFERENCES}

Adoption and Safe Families Act of 1997, P.L. 105-89, 111 Stat. 2115.

Allison, P. D. (1984). Event history analysis: Regression for longitudinal data. Newbury Park, CA: Sage Publications.

Benedict, M. I., White, R. B., \& Stallings, R. (1987). Race and length of stay in foster care. Social Work Research \& Abstracts, 23(4), 23-26.

Berry, M. (1992). An evaluation of family preservation services: Fitting agency services to family needs. Social Work, 37, 314-321.

Briar-Lawson, K. (1998). Capacity-building for integrated family-centered practice. Social Work, 43, 539-550.

Cole, E. (1995). Becoming family-centered: Child welfare's challenge, Families in Society, 76, 163-172.

Courtney, M. E. (1992). Reunification of foster children with their families: The case of Califormia's children. Unpublished dissertation. University of California at Berkeley.

Courtney, M. E. (1994). Factors associated with reunification of foster children with their families. Social Service Review, 68, 81-108.

Davis, I., \& Ellis-MacLeod, E. (1994), Temporary foster care: Separating and reunifying families. In J. Blacher (Ed.), When there's no place like home: Options for children living apart from their natural families (pp. 123-161). Baltimore: Paul H. Brookes.

Fanshel, D. (1976). Status changes of children in foster care: Final results of the Columbia Longitudinal Study. Child Welfare, 55, 143-171.

Festinger, T. (1996). Going home and returning to foster care, Children and Youth Services Review, 18, 383-402.

Finch, S. J., Fanshel, D., \& Grundy, J. F. (1986). Factors associated with the discharge of children from care. Social Work Research \& Abstracts, 22(1), 10-18.

Fraser, M. W., Nelson, K. E., \& Rivard, J. C. (1997). Effectiveness of family preservation services. Social Work Research, 21, 138-153.

Goerge, R. M. (1990). The reunification process in substitute care. Social Service Review, 64, 422-457.

Jenkins, S., \& Diamond, B. (1985). Ethnicity and foster care: Census data as predictors of placement variables. American Journal of Orthopsychiatry, 55, 267-276.

Lawder, E., Poulin, J., \& Andrews, R. (1986). A study of 185 foster children 5 years after placement. Child Welfare, 65, 241-251.

Lewandowski, C. A., \& Pierce, L. (2002). Assessing the effect of family-centered out-of-home care on reunification outcomes. Research on Social Work Practice, 12, 205221.

Lindsey, D. (1994). The welfare of children. New York: Oxford University Press.

Luke, D. A. (1993). Charting the process of change: A primer on survival analysis. American Journal of Community Psychology, 21, 203-246.

McMurtry, S. L., \& Gwat-Yong. L. (1992), Differential exit rates of minority children in foster care. Social Work Research \& Abstracts, 28(1), 42-48. 
Milner, J. (1987). An ecological perspective on duration of foster care. Child Welfare, 66, 113-123.

Nelson, K. E., \& Landsman, M. J. (1992). Alternative models of family preservation: Family-based services in context. Springfield, IL: Charles C Thomas.

SPSS, Inc. (1999). Cox regression analysis. SPSS Advanced Models. Chicago: Author.

Terling, T. (1999). The efficacy of family reunification practices: Reentry rates and correlates of reentry for abused and neglected children reunited with their families. Child Abuse \& Neglect, 23, 1359-1370.

U.S. Department of Health and Human Services. (2000). Rethinking child welfare practice under the Adoption and Safe Families Act of 1997: A resource guide. Washington, DC: U.S. Government Printing Office.

Walton, E. (1998). In-home family-focused reunification: A six-year follow-up of a successful experiment. Social Work Research, 22, 205-214.

Wells, K., \& Tracy, E. (1996). Reorienting intensive family preservation services in relation to public child welfare practice. Child Welfare, 75, 667-692.

Willet, J. B., \& Singer, J. D. (1993). Investigating onset, cessation, relapse, and recovery: Why you should, and how you can, use discrete-time survival analysis to examine event occurrence. Journal of Counseling and Clinical Psychology, 61, 952-965. 